\title{
Hospital Hygiene Maternity Hospital Public Lubumbashi Democratic Republic of Congo
}

\author{
Kaj Françoise Malonga ${ }^{1}$, Hendrick Lukuke Mbutshu ${ }^{1 *}$, Jean-Jacques Lunda Ngandu', \\ Mukengeshayi Abel Ntambue', Michel Makoutode²
}

\author{
${ }^{1}$ School of Public Health, University of Lubumbashi, Lubumbashi, DR Congo \\ ${ }^{2}$ Regional Institute of Public Health, Ouidah, Benin Republic \\ Email: ${ }^{* h e n d r i c k m b u t s h u @ g m a i l . c o m ~}$
}

How to cite this paper: Malonga, K.F., Mbutshu, H.L., Lunda Ngandu, J.-J., Ntambue, M.A. and Makoutode, M. (2017) Hospital Hygiene Maternity Hospital Public Lubumbashi Democratic Republic of Congo. Open Journal of Preventive Medicine, 7, 7485.

https://doi.org/10.4236/ojpm.2017.74007

Received: April 1, 2017

Accepted: April 27, 2017

Published: April 30, 2017

Copyright $\odot 2017$ by authors and Scientific Research Publishing Inc. This work is licensed under the Creative Commons Attribution International License (CC BY 4.0).

http://creativecommons.org/licenses/by/4.0/

\begin{abstract}
Introduction: Public hospitals in the DRC are of significant disrepair, while there is a strong link between the failure of hospital hygiene and the incidence of nosocomial infections. We have conducted a study with the objective of evaluating the structural-functional conditions of hospital hygiene maternity wards of public hospitals in Lubumbashi. Methodology: It was a descriptive cross-sectional study and structural-functionalist whose population consisted of nurses responsible for 7 of 12 maternity hospitals which were selected based on the inclusion criteria. The observation with an observation guide and maintenance using a questionnaire we used to collect data. Results: The results showed that hospital hygiene conditions in maternity wards of public hospitals in Lubumbashi are not good because almost all maternity services and surgery are not always water in the taps (14.3\%). The bins were a means for care units, no coding system exists to distinguish the type of waste. The medical waste are mixed and the other waste are burned in the open or in makeshift incinerator with other types of waste. Conclusion: These maternity wards have poor hygiene, staff responsible for this sector did not follow any training in this area. There is need to regulate the sector and train them.
\end{abstract}

\section{Keywords}

Hospital Hygiene, Maternity, Hospital Waste Management

\section{Introduction}

Public hospitals in the Democratic Republic of Congo (DRC) have formed in the early postcolonial reference for Central Africa, but with the deterioration of political reforms of the $80 \mathrm{~s}$ and $90 \mathrm{~s}$, these hospitals have sunken into their management system and were completely destroyed thus creating unhygienic 
conditions.

Hospital hygiene is concerned with the prevention of nosocomial infections and any kind of hospital met nuisance.

Preventing these Nosocomial Infections is a requirement for the quality of care we provide to people. The security and safety of care require a rigorous application of the rules on hospital hygiene. There is a close link between the failure of hospital hygiene and the incidence of nosocomial infections [1] [2].

This is what justifies the need to assess the hospital hygiene and knowledge of responsible officers involved in hospital hygiene activities.

Worldwide, many laws exist, including public health codes that register among the missions of all care facilities, the organization of hospital hygiene service and the fight against nosocomial infections, which implies the establishment committee against nosocomial infections in private establishment than public.

In Africa, the hospital hygiene conditions are not favorable in most countries, several surveys have shown not only that hospitals are facing financial problems, staff training, but also lack of organic frameworks that's care of hospital hygiene. A case biomedical waste management poses a real public health problem and environment in Africa, in Congo Brazzaville, for example, the estimated annual minimum production of this waste is about 341 tons for hospitals and laboratories. Health facilities do not have policies or biomedical waste management guidelines. They have not for the most appropriate and organized hospital hygiene services.

In Lubumbashi, public hospitals which are those that can provide complementary package of health care to the whole layer of the population are deemed by the deterioration of sanitary conditions as various reports and studies have repeatedly denounced the [3] [4] [5] [6].

Our 2011 study at the General Hospital Jason Sendwe revealed that the conditions of biomedical waste management and housekeeping at this hospital were evil. There was no water ( $81.1 \%$ of units/services surveyed) and there was a presence of odors during the period of this study. The transport of waste to the disposal site is primarily being done with the use of plastic buckets or ordinary bag hand-held or worn on the head and final treatment of waste was burning and burning in open, while the hospital was producing about $92 \mathrm{~kg} /$ day of biomedical waste [7].

The unsanitary conditions expose not only patients and visitors, but also health workers to the risk of nosocomial infections and blood exposure accidents. The initial training of health care providers in our country does not give sufficient credit in the course of general hygiene and hospital hygiene in particular. This situation should be remedied by ongoing job training, unfortunately, this type of training is rare in our structures.

Another study conducted at the hospital Sendwe had shown that providers of care are not trained on hospital hygiene jobs [8].

From the scientific point of view, in the DRC in general and Lubumbashi in particular, there's no scientific research has been conducted to determine the 
conditions for hospital hygiene of public maternity hospitals whereas in a previous study we identified still in hospital Jason Sendwe, a high rate of incidence of blood exposure accidents among caregivers likely related to poor conditions of hospital hygiene, including poor adherence to universal precautions and inadequate management of waste' care activities [8] [9].

Furthermore, the absence of a national policy on hospital hygiene would be an important factor in poor hygiene conditions, since the purpose of implementing the national hospital hygiene policy is to decom Institutional and technical structures through the establishment of networks that facilitate the adoption and application of hospital hygiene standards [10].

The Hygiene Code project DRC emphasizes the responsibility of the health facilities in declaration of contagious diseases, reporting of deaths related to diseases, the handling of bodies of victims of contagious diseases, buildings morgues and management of biomedical waste [11].

Noted subsequently that the result of a lack of hospital hygiene by always manifests the high incidence of nosocomial infections or care-associated infections are a heavy Event consequences not only in terms of morbidity and mortality, but also cost. Its prevention is essential, as well as control the spread and constitutes hospital hygiene measures including general all clinical, microbiological and epidemiological aspects of these infections but also the organization of care, maintenance of hospital equipment, management of the environment, the protection of employees. It is an indicator of quality of care and safety [12].

Our problem is its particularity maternity because of published reports annually on maternal and newborn. Approximately 2.7 million newborns die each year, and 2.6 million more children are stillborn. It is essential that all births take place in the presence of skilled health professionals in cleaner environment, to save the life of mother and child [13] [14] [15].

All this will, raise a research question whose answer is the results of our survey: What is the level of hospital hygiene in public hospitals in Lubumbashi?

The general objective of this part was to evaluate the structural-functional conditions of hospital hygiene maternity wards of public hospitals in Lubumbashi.

\section{Methods}

The Lubumbashi public hospitals have an average $5 \pm 3.4$ birthing tables. Nursing A1 are on average $3 \pm 0.7$, A2 on average $3 \pm 0.5$. The university hospitals, the General Hospital and Jason Sendwe Hospital Society of Railways of Congo have doctors gynecologists.

We conducted a descriptive study and cross-structural-functionalist in maternity wards of public hospitals in Lubumbashi.

The population consisted of nurses responsible for public hospital maternity Lubumbashi. For hospitals, all the 11 general hospitals and reference the University Clinics of Lubumbashi were concerned, was included, hospital whose 
authorities have answered positively to our request.

For staff, was included in the study, all nurses responsible maternity hospitals Lubumbashi selected in these public hospitals selected from Lubumbashi to this service and who agreed to answer our questions.

This is a non-probability sampling method which was constituted under the criteria for inclusion and exclusion. Data collection was carried out exhaustively in charge of maternity nurses. All general hospitals of reference and university clinics of Lubumbashi were involved in the study a total of 12 of which 7 were selected according to the authorities gave us the opportunity to access the desired data.

In total, we interviewed seven nurses responsible maternity that constituted our sample.

While the observation concerned the state instead of surfaces and equipment used to motherhood and the existence of the essential components of hospital hygiene, including: clean delivery tables, sinks, the existence of water, disinfectants, hand washing facilities, sanitary facilities...

We made use of the following techniques: semi-structure maintenance by making use of both administered questionnaires sent to nurses responsible maternity.

The structured and functional observation made use of an observation guide to some surfaces and equipment from their macroscopic state of cleanliness.

An evaluation criterion for assessing the state of place hospital surfaces has been previously established: Very good = flawless (new equipment), Good = some kinks, Good = very visible defects, but can be used, Bad = hardware or equipment affected and can not give the expected results and very bad is very faulty equipment for deallocating.

To facilitate certain statistical analyzes, the different modalities have been reduced to two, is good to refer to very good, good, good and bad enough to designate what is bad and very bad.

The data was encoded in double data entry on Excel 2010, and analyzed in Epi Info Version 7 by resorting to the usual statistics to describe our samples and calculate the frequency measurements.

The protocol was approved by the Ethics Committee of the University of Lubumbashi, we asked by agreement of these hospitals.

\section{Results}

Of the seven public hospitals surveyed, it emerges that all the rooms using natural ventilation for their aeration, Poupinel (dry heat sterilization) was the sterilization method used by almost all maternity wards of these hospitals, state clamps used for deliveries in four was good, bad in three and five structures had birthing messy tables. Soumamous (a local solution composed of: pine oil, formalin, sodium ether sulfate, boric acid, urea, fragrance and dye) were used for maintenance of premises and Dakin for skin and mucos (Table 1).

The investigating staff consisted of $100 \%$ of nurses responsible for maternity 
services in public hospitals Lubumbashi including 4 of them were in the age between 31 and 40, two between 20 and 30 years and was 53 years old. The majority had a length of between 6 and 10 years of service and six out of seven were married. Compared with the level of education, 57.1\% were nurses A1 (graduated 3 years), $28.6 \%$ were A2 (high school graduate) and $14.3 \%$ were level L2 (graduated 5 years university) (Table 2).

He was a civil tap in all maternity wards and operating rooms of these structures, however, there was no permanence of water in the taps, three maternity

Table 1. Hygiene materials and hospitality.

\begin{tabular}{|c|c|c|c|c|c|c|c|}
\hline & \multicolumn{7}{|c|}{ HOSPITALS } \\
\hline & $\begin{array}{c}\text { HGR } \\
\text { Kenya }\end{array}$ & $\begin{array}{c}\text { HGR } \\
\text { Kisanga }\end{array}$ & $\begin{array}{c}\text { HGR } \\
\text { Katuba }\end{array}$ & CUL & $\begin{array}{c}\text { HGR } \\
\text { Kampemba }\end{array}$ & $\begin{array}{c}\text { Hospital } \\
\text { SNCC }\end{array}$ & $\begin{array}{c}\text { HGR } \\
\text { Sendwe }\end{array}$ \\
\hline Type of ventilation & Natural & Natural & Natural & Natural & Natural & Natural & Natural \\
\hline Presence of disinfectants & Yes & Yes & Yes & Yes & Yes & Yes & Yes \\
\hline Types disinfectants on the skin and mucosa & Dakin & Dakin & Iodised alcohol & Dakin & Dakin & Dakin & Dakin \\
\hline Types of inert disinfectants & Soumamous & Soumamous & Soumamous & Soumamous & Soumamous & Soumamous & Soumamous \\
\hline The quality pliers and scissors & Bad & Good & $\mathrm{Bad}$ & Good & Good enough & $\mathrm{Bad}$ & Good \\
\hline Type sterilizer & Poupinel & Poupinel & Poupinel & Poupinel & Poupinel & Poupinel & Autoclave \\
\hline Disinfection tables after childbirth & Yes & Yes & No & Yes & Yes & Yes & No \\
\hline Cleanliness of deliveries table & No & Yes & No & No & No & Yes & No \\
\hline
\end{tabular}

HGR: General Reference Hospital; CUL: University Clinics in Lubumbashi; WC: water close; SNCC: National Society of Congo Railways.

Table 2. Sociodemographic parameters investigated.

\begin{tabular}{cccc}
\hline Settings & & & \\
\hline Sex & Modalities & Numbers & $\%$ \\
Study level & Female & 7 & 100 \\
& Modalities & Numbers & $\%$ \\
& A1 & 4 & 57.1 \\
Civil status & A2 & 2 & 28.6 \\
& L2 & 1 & 14.3 \\
& Modalities & Numbers & \\
Age in years & Married & 6 & 85.7 \\
& Single & 7 & 14.3 \\
& Modalities & Numbers & \\
& 20 to 30 years & 2 & 28.6 \\
& 31 to 40 & 4 & 57.1 \\
& 41 more & 1 & 14.3 \\
& Modalities & Numbers & $\%$ \\
& 1 to 5 years & 1 & 14.3 \\
& 6 to 10 years & 4 & 57.1 \\
& 11 more & 2 & 28.6 \\
\hline
\end{tabular}

L2: Licence in Nursing; A1: Graduate in Nursing; A2: Graduated from High School. 
hospitals in the seven surveyed had a liquid soap. The average WC was $4 \pm 0.7$ et shower was $3 \pm 1$. Only WC Cliniques Universitaires had running water during the period of the investigation. No pregnancy was normal device for hand washing (Table 3).

It emerges from this table that all these sinks were filthy maternity except that of the HGR Kisanga maternity Each had at least one tap, except HGR Sendwe who was nine. All operating rooms had a multi-purpose hand brush for surgical scrub. Placentas management is done in a placenta pit Sendwe except where they made use of a makeshift incinerator (Table 4).

In all these medical waste structures are visible in different corners of buildings or pavilions.

The number of garbage was an average per unit of care, no coding system existed to distinguish the type of waste. The packaging was done in a trash all sorts of waste: Waste similar to household waste, waste of infectious risk in care activities and hazardous waste. The medical waste, the Waste similar to household waste and other risk waste or hazardous waste were all mixed and burned either in the open or in makeshift incinerator with other types of waste stored in dumps or buried on site. Stillbirths were either given to relatives or buried in the grounds of the hospital in a space called graveyard of angels (Figure 1).

Table 3. Parameters of thegeneral hygiene.

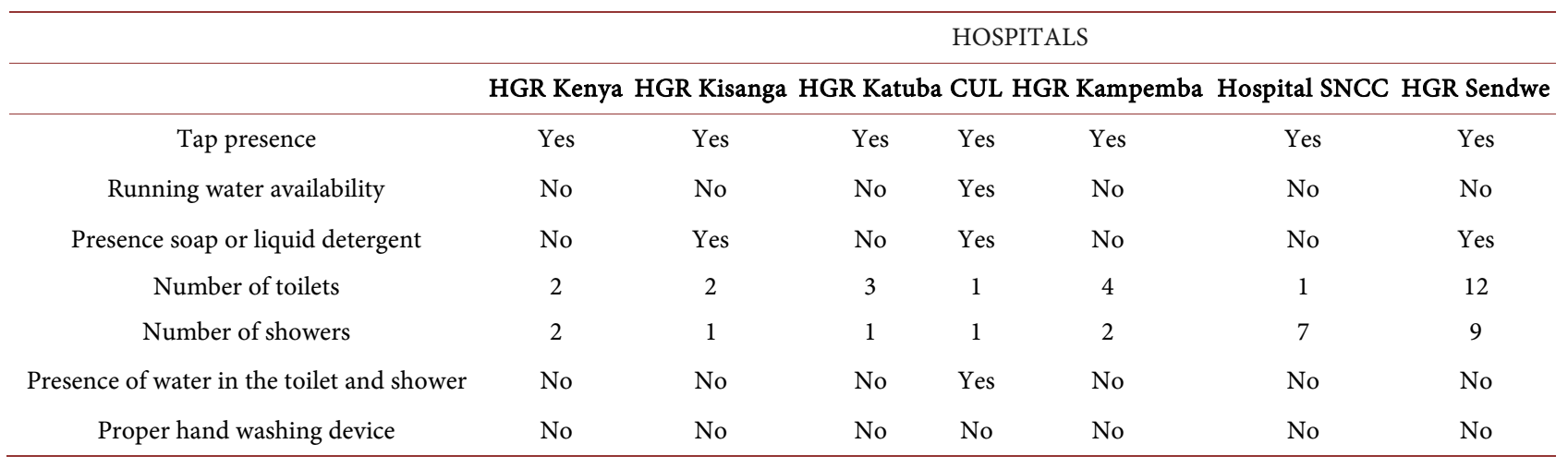

HGR: General Reference Hospital; CUL: University Clinics in Lubumbashi. WC: Water Close; HH: Hospital Hygiene; SNCC: National Society of Congo Railways.

Table 4. Observation of staff hygiene and hand hygiene.

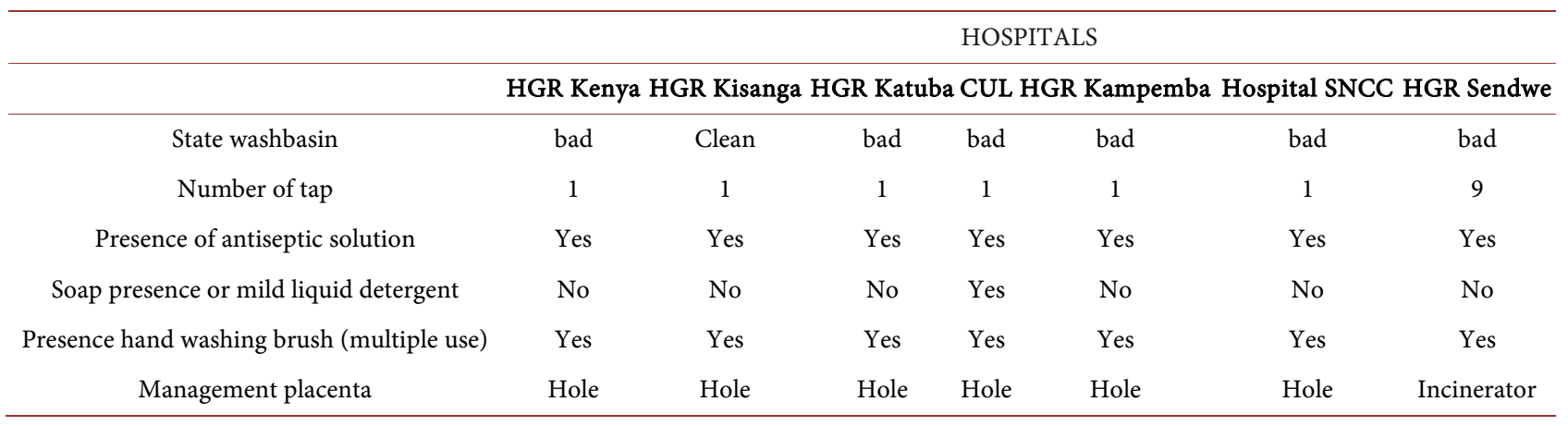

HGR: General Reference Hospital; CUL: University Clinics in Lubumbashi, SNCC: National Society of Congo Railways. 
Compared to the safety of personnel, wearing gloves and jacket were elements of the standard precautions that have been observed when working. While the deck port was observed in both structures. No structures are organized unit or hospital hygiene service. The renewal of the blouse to motherhood was done for the majority after a week of work (Table 5).

\section{Discussion}

In view of the work that had as objective to evaluate the structural-functional conditions of hospital hygiene maternity wards of public hospitals in Lubumbashi.

In view of the results as presented in the following paragraphs, we can say that our study method has enabled us to achieve the goal we set ourselves.

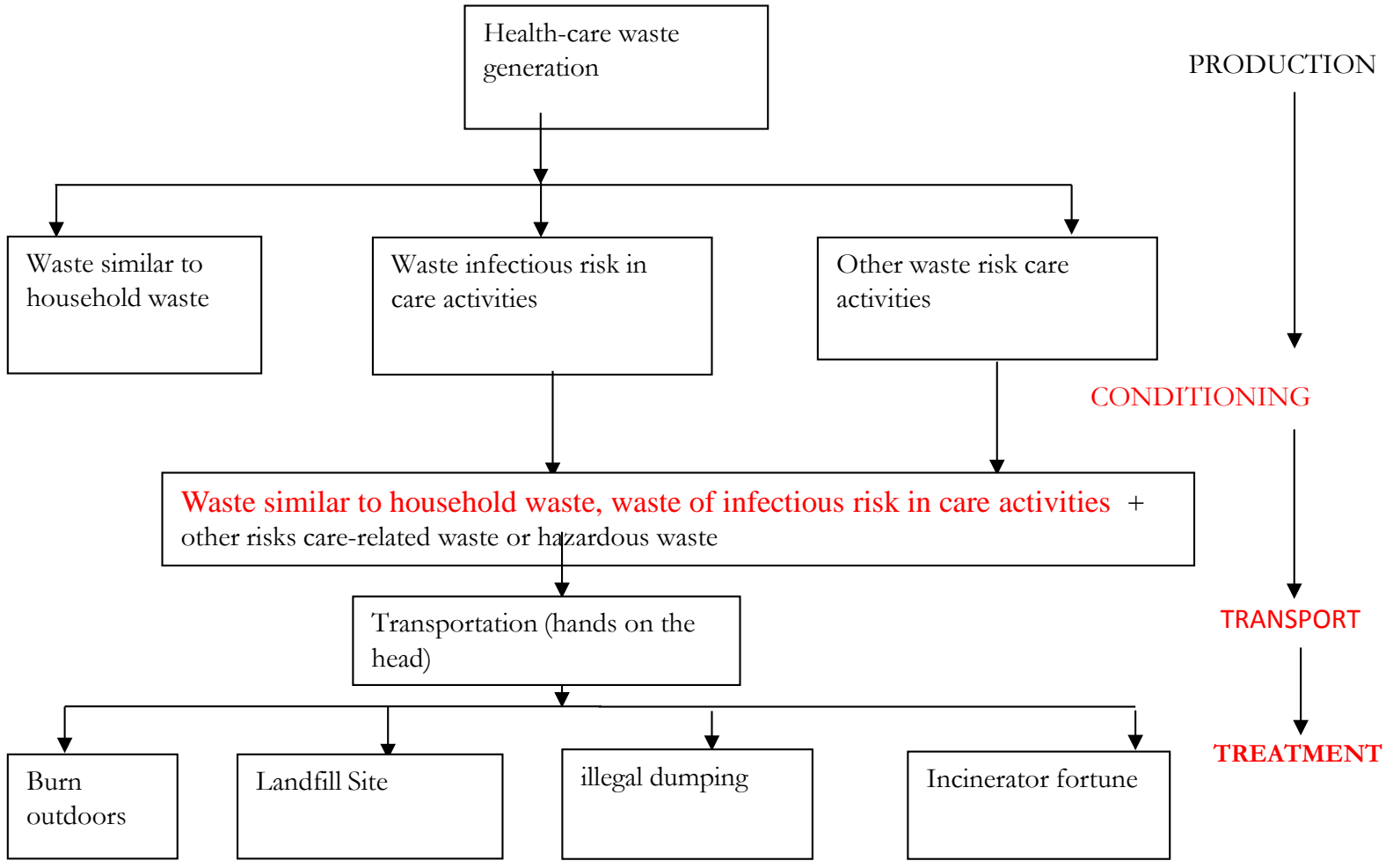

Figure 1. The summary diagram of the steps care activities waste management products in maternity wards of public hospitals in Lubumbashi.

Table 5. Staff security against the risk of BSE contamination and different.

\begin{tabular}{|c|c|c|c|c|c|c|c|}
\hline & \multicolumn{7}{|c|}{ FACILITY } \\
\hline & \multicolumn{3}{|c|}{ HGR KENYA HGR KisangaHGR Katuba } & \multirow{2}{*}{$\begin{array}{c}\text { CUL } \\
\text { Yes }\end{array}$} & \multicolumn{3}{|c|}{ HGR Kampembahospital SNCC HGR Sendwe } \\
\hline Wear gloves when working & Yes & Yes & Yes & & Yes & Yes & Yes \\
\hline Port apron & No & No & No & Yes & No & No & Yes \\
\hline Port jacket & Yes & Yes & Yes & Yes & Yes & Yes & Yes \\
\hline Existence of support units for victims of AES & No & Yes & No & Yes & No & No & Yes \\
\hline Presence service unit or $\mathrm{HH}$ & No & No & No & No & No & No & No \\
\hline
\end{tabular}

HGR: General Reference Hospital; CUL: University Clinics in Lubumbashi, HH: Hospital Hygiene; SNCC: National Society of Congo Railways. 


\subsection{Hotel Hygiene and Materials}

Compared to the hospitality hygiene and materials, all rooms used for manual ventilation, chlorine-based products and "Soumamous" (local solution composed of: pine oil, formalin, sodium ether sulfate, boric acid, urea, fragrance and dye) were used for this housekeeping and Dakin skin and mucosa. The Poupinel (dry heat sterilization) was the sterilization method used by almost all maternity clinics and surgeries of these hospitals. On the seven structures surveyed, the disconnecting used for deliveries in three was good, bad and good enough in three in a structure. This poses a serious problem that the WHO recommends sterilization by moist heat, which is a means of sterilization has to be the most used primarily by hospitals for reusable devices because it is the only active means of prions in the present state of knowledge [15] [16].

Five structures were unclean birthing tables. He was a civil tap in all maternity wards and operating rooms of these structures, however it does not Y'avait permanence of water in the taps, only three maternities of the seven surveyed had a mild liquid soap hand hygiene.

The average WC was $4 \pm 0.7$ et shower was $3 \pm 1$. Only WC Cliniques Universitaires had running water continuously during the period of the investigation.

In the literature it is recognized that the development of hospital hygiene through the centuries has been closely following the technical access to running water for the improvement of care for patients in hospitals [17] [18] [19]. The lack of water in the hospital tap hamper hospital hygiene conditions.

According to a study by the World Health Organization and the United Nations Children's Fund in March 2015 66,000 care facilities, 40\% of whom approximately lacked running water, more a third of establishments had no soap for washing hands and a fifth did not have toilets.

It is virtually impossible to talk about hospital hygiene without referring to the permanent availability of water in the taps, demonstrating basks in before the failure of these structures for hospital hygiene [17]. Note that this is purest in Lubumbashi with alarming proportions compared to other studies.

\subsection{Personal Hygiene and Hand Hygiene}

Already in early 19 sciecle several researchers have shown the relationship between hygiene and infection control, including Ignace Philippe Semmelweis who showed evidence between handwashing to fight against infections women after childbirth and Louis pastor who discovered the existence of microbes and promotes asepsis [17].

In our study, all of these sinks were filthy maternity except those of HGR Kisanga no structure had good hand-washing device. All operating rooms had a hand brush, but multiple use for surgical scrub instead and in place of the disposable brush. Lack of water and hand washing devices do not promote handwashing practice.

While hand hygiene is considered the most important measure for prevention 
of nosocomial infections and the spread of pathogens resistant to antibiotics [20] [21] [22].

Our results are not in the room for those who have found that the rate of adherence to the nursing staff hand hygiene-related practices remains low with an average compliance rate of $40 \%$ [17] [23] [24].

This view was reaffirmed by Mary and others, who found that compliance by healthcare workers remains a problem worldwide. The reasons given by our study are those found in these studies that have found that this poor compliance is due to the lack of water points and the poor tolerance of some antiseptic soaps [25] [26] [27].

\subsection{Hospital Waste Management}

In our study, the medical waste were mixed and other waste burned in the open or in makeshift incinerator with other types of waste for lack of bins to sort the collection and incinerator to incinerate properly according to regulations. The number of bins were a means for care units, no coding system has existed for distinguishing the type of waste and direct their average salary. These results corroborate those of other research in the developing countries, like that of Congo Brazzavillehospitals have no policy or biomedical waste management guidelines have no suitable and organized hospital hygiene services and biomedical throw solid waste in dumps.

However, a study by Zaïsonou J and allies on the evaluation of the quality of the management of solid biomedical waste in Benin collected in fairly good results unlike other. This difference may be due to the fact that in this country there is a hospital hygiene policy and actors are sensitized through a committee against nosocomial infections on biomedical waste management [7] [28].

\subsection{Security Staff}

Compared to the safety of personnel during the observation and interview with responsible nurses, we found they wear the gloves and jacket at work. These results show how the structures do not pay interest in the prevention of accidents of exposure to blood as it is known that the installation of safety equipment is a major element of primary prevention of accidents of exposure to blood.

The application of measures to protect healthcare contamination risks in an accident involving exposure to blood and body fluids should also help to ensure the safety vis-à-vis the same risk patients [29] [30]. This hampers the quality of care, for the prevention of BSE fits into the context of improving the quality of patient care and improving the working conditions of staff.

In our study, no structure was organizing a unit or hospital hygiene service or support personnel in case of accidents of exposure to blood. It was also found non-compliance with universal precautions because when observing, staff décapuchonnait needles, hand washing instructions were not followed. This is linked to the lack of training of personnel in hospital hygiene and lack of 
resources to equip the personnel protective equipment.

\section{Conclusions}

In conclusion, we will retain in this study that hospital hygiene conditions in maternity wards of public hospitals in Lubumbashi are not good for lack of water. The bins are in short supply in a way by care unit, no coding system exists to distinguish the type of waste. The medical waste are mixed with other types of waste are burned in the open or in makeshift incinerator with other types of waste.

We must equip public hospitals in Lubumbashi in hospital hygiene equipment, supply them with running water and train personnel in hospital hygiene.

\section{Conflict of Interest}

The authors declare that no conflict of interest.

\section{References}

[1] Dauphin, A. and Darbord, A.D. (1998) Hygiene Practice. 2nd Edition, Editions Medical Internationals, Paris, 1-28.

http://www.youscribe.com/catalogue/livres/savoirs/hygiene-hospitaliere-pratique-2 -ed-2-tir-2393478

[2] Haxhe, J.J. (2004) Hospital Hygiene Concept. UCL.

[3] Public Health Training Center (2015) Makoutodé Million Regional Course on Hospital Hygiene and Nosocomial Infections and Infections Associated with Health Care and Services. Public Health Training Center, Lome Republic of Togo, Lome.

[4] National Technical Committee of Nosocomial Infections (1999) 100 Recommendations for Surveillance and Prevention of Nosocomial Infections. Ministry of Employment and Solidarity.

[5] MSP-DRC (2006) General Secretariat of Health. Building Strategy.

[6] Ministry of Health State of Play of the Health Sector (ELS) (1998) Kinshasa, Democratic Republic of Congo.

[7] Mbutshu, H.L., Ntambwe, A.M., Ngatu, R.N., Suganuma, N., Wembonyama, N. and Kabyla, I. (2013) Management of Care Activities Waste and Maintenance of Premises at the Referral Hospital Jason Sendwe Lubumbashi, Democratic Republic of Congo. Hygiene, 21, 159-162.

[8] Ngatu, N.R., Phillips, E.K., Wembonyama, O.S., Hirota, R., Kaunge, N.J., Mbutshu, L.H., et al. (2012) Practice of Universal Precautions and Occupational Risk of Viral Infection Blood-Terminal among Congolese Health Care Workers. Journal of Infection Control, 40, 68-70.

[9] Mayon-White, R.T., et al. (1988) An International Survey of the Prevalence of Hospital-Acquired Infection. Journal of Hospital Infection, 11, 43-48.

[10] Ministry of Health (2006) Decree No. 2006-087 du 0my 8r20 s06 with the Approval of the National Policy on Hospital Hygiene Republic of Benin.

[11] Minister of Public Health (2015) Hygiene Code of the Democratic Republic of Congo.

[12] Pittet, D., Allengranzi, B., et al. (2006) Evidence-Based Model for Hand Transmission during Patient Care and the Role of Improved Practices. The Lancet 
Infectious Diseases, 6, 641-652.

[13] UNICEF, WHO, The World Bank, and United Nations Population Division (2013) The Inter-Agency Group for Child Mortality Estimation (IGME A) Levels and Trends in Child Mortality. Report, UNICEF, New York.

[14] Conde-Agudelo, A., Belizan, J.M. and Lammers, C. (2004) Maternal-Perinatal Morbidity and Mortality Associated with Teenage Pregnancy in Latin America: Cross-Sectional Study. American Journal of Obstetrics and Gynecology, 192, 342349.

[15] Chenge, M., Van der Vennet, J., Porignon, D., Luboya, N., Kabyla, I. and Criel, B. (2010) The Health card Lubumbashi, Democratic Republic of Congo Part II: Analysis of the Operational Activities of Health Facilities. Global Health Promotion, 17, 75-84. https://doi.org/10.1177/1757975910375174

[16] Makoutodé, M. (2005) Prevention of Nosocomial Infections CNHU-HKM What Challenges? The Quality Approach to Hospital. 7th Dating Hospitalières of RESHAOC, Cotonou. http://slideplayer.fr/slide/5117141/

[17] Myriam, H. (2009) Care Aides. Hygiene and Prevention of Nosocomial Infections; Reference Review Care Giver. No. 27, 1-4.

[18] Jamie, B., Ryan, C., Maggie, M., Bruce, G., Maria, N., Edward, K., et al. (2015) Lack of Toilets and Clean Water in Health Facilities. Bulletin of the World Health Organization, 93, 210.

[19] WHO (2006) Why a Global Challenge on Nosocomial Infections.

[20] WHO (2009) WHO Summary of Recommendations for Hand Hygiene in the Soins. Premier Global Challenge for Patient Safety Clean Care Is Safer Care. WHO/IER/PSP.

[21] Larson, E. (1988) A Causal Link Entre Hand Washing and Risk of Infection? Examination of Evidence. Infection Control and Hospital Epidemiology, 9, 28-36.

https://doi.org/10.2307/30144131

[22] Pittet, D., Hugonnet, S., et al. (2000) Effectiveness of a Hospital-Wide Program to Improve Compliance with Hand Hygiene. Infection Control Program. The Lancet, 356, 1307-1312.

[23] Haas, J.P. and Larson, E.L. (2008) Compliance with Hand Hygiene Guidelines: Where Are Win in 2008? The American Journal of Nursing, 108, 40-44. https://doi.org/10.1097/01.NAJ.0000330260.76229.71

[24] Gould, D., Chudleigh, J.H., et al. (2007) Interventions to Improve Hand Hygiene Compliance in Patient Care. The Cochrane Database of Systematic Reviews, 2, 1-18. https://doi.org/10.1002/14651858.cd005186.pub2

[25] Maury, E., Alzieu, M., Baudel, J.L., Haram, N., Barbut, F., Guidet, B. and Offenstadt, G. (2000) Availability of an Alcohol Solution Can Improve Hand Disinfection Compliance in an Intensive Care Unit. American Journal of Respiratory and Critical Care Medicine, 162, 324-327. https://doi.org/10.1164/ajrccm.162.1.9908118

[26] Boyce, J.M. and Pittet, D. (2000) Guideline for Hand Hygiene in Health-Care Settings: Recommendations of the Healthcare Infection Control Practices Advisory Committee and the HICPAC/SHEA/APIC/IDSA Hand Hygiene Task Force. Infection Control and Hospital Epidemiology, 23, S3-S40.

[27] Girard, R., Perraud, M., Prüss, S.A., Tikhomirov, E.M. and Thuriaux, V.P. (2008) Prevention of Nosocomial Infections, Practical Guide. 2nd Edition, WHO/CDS/ CSR/EPH.

[28] Saizonou, J., Ouendo, E.M., Agueh, V., Tokplonou, E. And Makoutodé, M. (2013) Assessment of the Quality of the Management of Solid Biomedical Waste in the 
Health Zone Klouékanmè-Toviklin-Lalo Benin. International Journal of Occupational Health, 1, 1-11.

[29] Hygienes (2010) Recommendations, Monitor and Prevent Healthcare Associated Infections. Hygienes, 18, 1-180.

[30] Gilles, B. (1998) Nosocomial Infections and Hospital Environment. Flammarion Medicine Science, Paris.

Submit or recommend next manuscript to SCIRP and we will provide best service for you:

Accepting pre-submission inquiries through Email, Facebook, LinkedIn, Twitter, etc. A wide selection of journals (inclusive of 9 subjects, more than 200 journals)

Providing 24-hour high-quality service

User-friendly online submission system

Fair and swift peer-review system

Efficient typesetting and proofreading procedure

Display of the result of downloads and visits, as well as the number of cited articles Maximum dissemination of your research work

Submit your manuscript at: http://papersubmission.scirp.org/

Or contact ojpm@scirp.org 